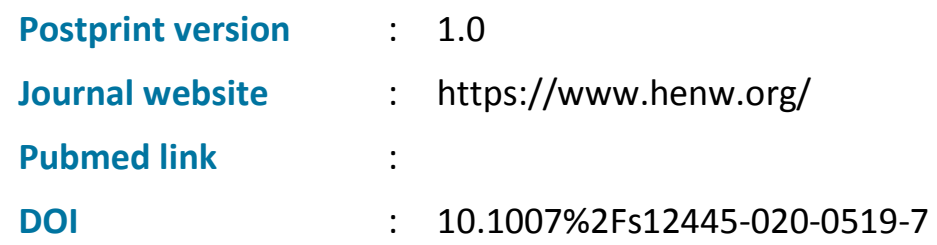

This is a Nivel certified Post Print, more info at nivel.nl

\title{
Waarom stijgt het aantal euthanasieverzoeken?
}

\author{
Marianne Heins, Gé Donker, Simone Versteeg, Joke Korevaar
}

Sinds 2002, toen de Wet toetsing levensbeëindiging op verzoek en hulp bij zelfdoding in werking trad, is het aantal euthanasieverzoeken gestegen. Het Nivel analyseerde de achterliggende factoren. Een samenspel van factoren is verantwoordelijk voor de groei van het aantal euthanasieverzoeken in de afgelopen vijftien jaar.

Na de invoering van de Wet toetsing levensbeëindiging op verzoek en hulp bij zelfdoding in 2002 steeg het aantal meldingen van euthanasie van zo'n 2000 per jaar in 2003 tot ruim 6500 in $2017 .{ }^{1}$ Patiënten deden door de jaren heen vaker een verzoek tot euthanasie en deze verzoeken werden ook vaker uitgevoerd. Dit roept vragen op naar de achterliggende redenen voor deze stijging. Daarom heeft het Nivel - in opdracht van het ministerie van Volksgezondheid, Welzijn en Sport - in kaart gebracht wat er vanaf 2002 bekend is over factoren die de ontwikkelingen in het aantal uitgevoerde euthanasieverzoeken beïnvloeden. ${ }^{2}$

\section{Wat is bekend?}

- Het aantal meldingen van euthanasie steeg van zo'n 2000 per jaar in 2003 tot 6585 in 2017.

\section{Wat is nieuw?}

- Vooral ouderen doen vaker een euthanasieverzoek dan voorheen en hun verzoeken worden ook vaker gehonoreerd.

- Het draagvlak voor euthanasie is toegenomen.

- Huisartsen zijn vaker betrokken bij het overlijden en ook meer dan vroeger bereid euthanasie te verlenen.

- De komst van de Levenseindekliniek heeft een kleine bijdrage geleverd aan de toename van het aantal levensbeëindigingen.

- De toename is niet veroorzaakt door het liberaler toepassen van euthanasie bij psychische aandoeningen, dementie of stapeling van ouderdomsklachten. 
Heins, M., Donker, G., Versteeg, S., Korevaar, J. Waarom stijgt het aantal euthanasieverzoeken? Huisarts en Wetenschap, 2020, 63(3), p. 23-26

\section{Methode}

In dit literatuuronderzoek is gekeken naar wetenschappelijke artikelen aan de hand van de volgende inclusiecriteria:

- beschrijft factoren die van invloed kunnen zijn op het

- aantal levensbeëindigingen bij mensen;

- betreft Nederland of België;

- bevat gegevens van 2002 tot 2018;

- beschikbaar in het Nederlands, Engels of Frans.

Allereerst werd in de databases PubMed en CINAHLgezocht naar originele onderzoeksartikelen en reviewartikelen met de volgende zoektermen: ((“Euthanasia”[Mesh] OR "Suicide, Assisted" [Mesh] OR euthanasia*[tiab] OR assisted suicide*[tiab] OR assisted death*[tiab] OR assisted dying[- tiab]) AND (Netherlands[tw] OR Dutch[tw] OR Benelux[tw] OR Belgium[tw] OR flanders[tw] OR wallonia[tw])) NOT (animals[mh] NOT humans[mh])

Er zijn grote verschillen tussen landen in de wet- en regelgeving rond euthanasie en hoelang deze al bestaat, maar de situatie in België is goed vergelijkbaar met die in Nederland. Daarom beperkten de onderzoekers zich tot literatuur uit Nederland en België. Artikelen die uitsluitend euthanasie bij dieren betroffen, zijn geëxcludeerd.

Publicaties zijn eerst gescreend op titel en abstract, waarbij de eerste $15 \%$ werd gescreend door twee onderzoekers om de selectiemethode af te stemmen. Beide onderzoekers bekeken vervolgens de volledige tekst van de geselecteerde artikelen en zochten in de referenties van de gevonden literatuur naar verdere relevante artikelen. De wetenschappelijke literatuur is aangevuld met 'grijze literatuur' die gevonden werd via Google of die bekend was bij de onderzoekers zelf of in hun netwerk. Hiervoor zijn drie experts op het gebied van euthanasie benaderd.

Aan de hand van twee theoretische kaders brachten de onderzoekers alle literatuur onder in verschillende thema's. ${ }^{3,4}$

\section{Resultaten}

Er werden 1874 wetenschappelijke artikelen gevonden, waarvan er 72 werden geïncludeerd. Ook werden er 57 rapporten en documenten gevonden. Hiervan werden er 28 geïncludeerd. Negenenzestig procent van de geïncludeerde artikelen betrof de Nederlandse situatie. Uit de gevonden literatuur bleek dat de stijging van het aantal levensbeëindigingen door artsen verband houdt met diverse factoren. Vijf mogelijk verklarende factoren zijn de vergrijzing van de bevolking, stijging van het onderwijsniveau van ouderen, het toegenomen draagvlak voor euthanasie, veranderingen in de zorg rond het levenseinde en veranderingen in doodsoorzaken. Daarnaast zijn enkele factoren gevonden die de stijging niet verklaren, zoals de toename in het aantal mensen met dementie en factoren waarvan de betekenis niet duidelijk is, zoals een stijging in het aantal euthanasieaanvragen bij psychiatrische aandoeningen.

\section{Vergrijzing van de bevolking}

Dat het aantal euthanasiemeldingen is gestegen, kan komen doordat de Nederlandse bevolking vergrijst. Ouderen hebben vaker ziekten die aanleiding kunnen geven tot een euthanasieverzoek, zoals kanker, dus is een navenante stijging in het aantal euthanasieverzoeken te verwachten. Tussen 2005 en 2015 steeg bij ouderen meer dan bij andere leeftijdsgroepen het aantal mensen waarbij euthanasie werd uitgevoerd [figuur]. ${ }^{1}$ Als de vergrijzing een grote rol speelt in de stijging van het aantal euthanasieverzoeken, verwacht je dat vooral het aantal ouderen bij wie euthanasie wordt uitgevoerd zal stijgen en dat deze stijging gelijke tred houdt met de algemene sterfte onder ouderen. Het aantal ouderen bij wie euthanasie wordt uitgevoerd stijgt echter veel sterker dan dit algemene sterftecijfer. ${ }^{5}$ De stijging van het aantal euthanasieverzoeken komt dus niet alleen door de vergrijzing. 
Heins, M., Donker, G., Versteeg, S., Korevaar, J. Waarom stijgt het aantal euthanasieverzoeken? Huisarts en Wetenschap, 2020, 63(3), p. 23-26

Ouderen zijn in de afgelopen vijftien jaar iets vaker een euthanasieverzoek gaan doen. In 2010 werd $65 \%$ van de euthanasieverzoeken gedaan door mensen van 65 jaar of ouder en was ook $65 \%$ van de overledenen 65 jaar of ouder; in 2015 was dit respectievelijk 73\% en $69 \%$. Bovendien is ook het percentage euthanasieverzoeken dat daadwerkelijk wordt uitgevoerd geleidelijk gestegen, vooral bij 80-plussers. In 2010 was dit percentage $56 \%$ bij mensen jonger dan 65 jaar, 49\% bij mensen tussen 65 en 79 jaar en 32\% bij mensen van 80 jaar en ouder; in 2015 was dit respectievelijk 56\%, 61\% en $49 \% .{ }^{1}$ De verschillen zijn dus een stuk kleiner geworden.

\section{Onderwijsniveau ouderen gestegen}

Een mogelijke verklaring waarom ouderen vaker een euthanasieverzoek doen is dat het onderwijsniveau van met name ouderen tussen de 65 en 74 jaar gestegen is (de stijging bij mensen van 75 jaar en ouder was maar beperkt). Uit Belgisch onderzoek blijkt dat mensen met een hoger onderwijsniveau vaker een euthanasieverzoek doen. ${ }^{2}$ Onze hypothese is dat mensen met een hoger onderwijsniveau mogelijk beter in staat zijn om de wens tot euthanasie te verbaliseren en mogelijk een grotere wens tot regie over het eigen levenseinde hebben. Onbekend is of er in Nederland ook daadwerkelijk meer euthanasieverzoeken worden gedaan door mensen met een hoger onderwijsniveau.

\section{Meer draagvlak voor euthanasie in Nederland}

Onder de Nederlandse bevolking is het draagvlak voor euthanasie toegenomen. Het grootste deel van de Nederlanders staat positief tegenover euthanasie: in 2002 was $12 \%$ van de Nederlandse bevolking tegen euthanasie, in 2011 en 2016 was dit nog 5\%. ${ }^{6}$ Mogelijk heeft de toegenomen tolerantie ten opzichte van euthanasie te maken met de daling van het aantal gelovigen in Nederland. ${ }^{7}$ Ook is gebleken dat vooral ouderen zich meer dan voorheen kunnen voorstellen dat zij ooit een euthanasieverzoek zullen doen bij hun arts. Tussen 2001 en 2008 steeg dit percentage onder ouderen van 64 tot 75 jaar van 58 naar $70 \%{ }^{8}$

\section{Zorg rond levenseinde veranderd}

De afgelopen vijftien jaar is de organisatie van de zorg rond het levenseinde veranderd. Mensen sterven minder vaak in het ziekenhuis en vaker thuis met de huisarts als primaire zorgverlener. ${ }^{9}$ Bovendien is er meer aandacht voor palliatieve zorg. ${ }^{10}$

Werd in 2005 41\% van de overlijdens begeleid door een huisarts, in 2015 was dit 49\%. Medisch specialisten zijn juist minder vaak betrokken bij de zorg rond het overlijden (33\% in 2005, $24 \%$ in 2015). In een onderzoek naar 3699 overlijdens bleek dat de 1725 gevallen waarbij een huisarts betrokken was vaker waren voorafgegaan door een euthanasieverzoek $(14 \%, n=233)$ dan de 1974 gevallen waarbij geen huisarts betrokken was $(3 \%, n=65) .11$ Dit komt mogelijk doordat huisartsen positiever staan tegenover euthanasie dan andere artsen. In een vragenlijstonderzoek rapporteerde 93\% van de huisartsen het denkbaar te vinden dat zij euthanasie zouden toepassen, tegenover $87 \%$ van de specialisten ouderengeneeskunde en $75 \%$ van de overige medisch specialisten. Het percentage huisartsen dat tegen euthanasie is (7\%), is sinds 2005 stabiel. ${ }^{1}$ Artsen die een euthanasieverzoek niet zelf willen of kunnen uitvoeren, hebben meer verwijsmogelijkheden gekregen.

In 2012 is de Levenseindekliniek opgericht (tegenwoordig Expertisecentrum Euthanasie); het aantal levensbeëindigingen door artsen van deze kliniek steeg van 133 in 2013 (18\% van het totaal aantal verzoeken) tot 727 in 2018 (28\% van het totaal aantal verzoeken). ${ }^{12}$ In Hoogeveen hebben huisartsen in 2012 onderling afspraken gemaakt over het uitvoeren van euthanasie voor gewetensbezwaarde huisartsen. Dit zogeheten 'Hoogeveens model' kreeg elders navolging. ${ }^{12,13}$ Ook als artsen weigeren zelf euthanasie uit te voeren, zijn steeds meer van hen bereid de patiënt door te verwijzen naar een andere arts: in 2005 gold dat voor 38\%, in 2011 voor $49 \% .{ }^{1}$ De Levenseindekliniek en het Hoogeveens 
Heins, M., Donker, G., Versteeg, S., Korevaar, J. Waarom stijgt het aantal euthanasieverzoeken? Huisarts en Wetenschap, 2020, 63(3), p. 23-26

model kunnen de toename van het aantal uitgevoerde euthanasieverzoeken echter niet volledig verklaren. Ook het aantal uitgevoerde euthanasieverzoeken waarbij het Expertisecentrum Euthanasie niet betrokken was, is gestegen. ${ }^{2}$

\section{Kanker relatief vaak reden voor euthanasieverzoek}

De doodsoorzakenstatistiek is de laatste vijftien jaar gekanteld. Het aantal mensen dat overleed aan kanker steeg van rond de 40.000 in 2005 tot iets boven de 45.000 in 2015, terwijl het aantal mensen dat overleed aan hart- en vaatziekten afnam van ongeveer 45.000 in 2005 tot ongeveer 38.000 in $2015 .^{13,14}$

\section{[Figuur]}

Dit heeft invloed gehad op het aantal euthanasieverzoeken. Kanker is relatief vaak een reden voor een euthanasieverzoek (twee derde van de euthanasieverzoeken is gerelateerd aan kanker), hart- en vaatziekten zijn dat veel minder ( $6 \%$ van de euthanasieverzoeken is gerelateerd aan een hart- en vaatziekte). ${ }^{1,14,15}$ Bovendien wordt een euthanasieverzoek van een patiënt met kanker vaker gehonoreerd. In 2015 werd 59\% van de euthanasieverzoeken van patiënten met kanker uitgevoerd en slechts $32 \%$ van de verzoeken van patiënten met hart- en vaatziekten. ${ }^{1}$

Aan euthanasie gaat meestal een palliatief traject vooraf en de laatste jaren is er meer aandacht gekomen voor palliatieve zorg. Uit een onderzoek onder niet-acute sterfgevallen in 2005 bleek dat van de patiënten die een palliatieve zorgconsulent hadden $23 \%$ een euthanasieverzoek had gedaan, tegenover slechts $6 \%$ van de patiënten die geen palliatieve zorgconsulent hadden. Ook als je corrigeert voor de reden van overlijden doen patiënten bij wie een palliatief zorgteam betrokken is bijna tweemaal zo vaak een euthanasieverzoek. ${ }^{11}$ De toegenomen aandacht voor palliatieve zorg kan dus ook een verklaring zijn voor het toenemend aantal euthanasieverzoeken, al kan het natuurlijk ook zo zijn dat de betrokkenheid van de palliatief zorgconsulent en het euthanasieverzoek beide te maken hebben met de lijdensdruk door de onderliggende ziekte en de zorgvuldigheidscriteria voor euthanasie.

\section{Niet vaker euthanasie bij psychiatrische aandoeningen en dementie}

Andere mogelijke verklaringen werden niet bevestigd door het literatuuronderzoek. Mensen met een psychiatrische aandoening deden in 2015 niet vaker een euthanasieverzoek dan mensen zonder een dergelijke aandoening. ${ }^{14,15}$ Ook bleek dat de kans dat een euthanasieverzoek wordt gehonoreerd relatief klein is wanneer het verzoek gedaan wordt om psychische redenen en niet vanwege een lichamelijke ziekte. ${ }^{15,16}$ Artsen vinden bij deze patiënten minder vaak dat aan de zorgvuldigheidscriteria is voldaan. ${ }^{16,17}$

Dementie of stapeling van ouderdomsklachten leiden bij slechts weinig patiënten tot een euthanasieverzoek en bieden ook geen verklaring voor de toename van het aantal (uitgevoerde) euthanasieverzoeken. ${ }^{2}$

\section{Beschouwing}

Uit dit literatuuronderzoek komen verschillende factoren naar voren die de stijging in het aantal uitgevoerde euthanasieverzoeken tussen 2003 en 2017 kunnen verklaren. Ten eerste doen ouderen vaker een euthanasieverzoek dan voorheen en worden hun verzoeken vaker uitgevoerd. Ten tweede speelt onbehandelbare kanker een steeds grotere rol rond het levenseinde en wordt die van hart- en vaatziekten juist kleiner. Ten derde is het draagvlak voor euthanasie binnen de Nederlandse bevolking toegenomen. En ten vierde hebben de komst van de Expertisecentrum Euthanasie en de grotere betrokkenheid van huisartsen bijgedragen aan het toegenomen aantal levensbeëindigingen. 
Heins, M., Donker, G., Versteeg, S., Korevaar, J. Waarom stijgt het aantal euthanasieverzoeken? Huisarts en Wetenschap, 2020, 63(3), p. 23-26

Deze toename is niet veroorzaakt door het liberaler toepassen van euthanasie bij psychische aandoeningen, dementie of stapeling van ouderdomsklachten.

Huisartsen krijgen door de vergrijzing, veranderde doodsoorzaken en groter draagvlak binnen de bevolking vaker te maken met patiënten die een euthanasieverzoek doen. Zij zijn over het algemeen bereid om deze verzoeken ook uit te voeren wanneer aan de zorgvuldigheidscriteria is voldaan. En wanneer zij een euthanasieverzoek niet zelf kunnen of willen uitvoeren, zijn er meer verwijsmogelijkheden dan vroeger.

\section{Sterke punten en beperkingen}

Zoals bij elk literatuuronderzoek zijn onze resultaten afhankelijk van de beschikbare literatuur. Het is mogelijk dat belangrijke factoren niet onderzocht en dus gemist zijn. We zijn bij het opstellen van dit onderzoek daarom uitgegaan van twee theoretische kaders rond factoren die zorggebruik beïnvloeden en factoren die een medische beslissing beïnvloeden. ${ }^{3,4}$ De beschikbare literatuur hebben we geordend aan de hand van de thema's in deze kaders.

\section{Aandachtspunten voor de huisartsenpraktijk}

Een factor die in de gevonden literatuur niet aan bod kwam, was het beleid van zorginstellingen. Wat is de invloed van de toegenomen samenwerking tussen huisartsen en tussen huisartsenpraktijken? Hoe zijn de bestuurders en de artsen zelf daarbij omgegaan met eventuele verschillen in euthanasiebeleid? Hoe expliciet moeten huisartsen hun bereidheid tot levensbeëindiging uitdragen? Moet informatie daarover op de praktijkwebsite staan? Met uitzondering van de groep huisartsen die het Hoogeveens model ontwikkelde, is er weinig bekend over het beleid van huisartsengroepen op het gebied van euthanasie. ${ }^{12,13}$ Dit geeft stof tot nadenken en tot nader onderzoek, want het grootste deel van de euthanasieverzoeken wordt uitgevoerd door de huisarts, bij de patiënt thuis.

\section{Conclusie}

Uit dit literatuuronderzoek blijkt dat niet één factor, maar een samenspel van factoren van invloed is geweest op de ontwikkeling van het aantal uitgevoerde euthanasieverzoeken in de afgelopen vijftien jaar. Mogelijk verklarende factoren zijn de vergrijzing, meer sterfte aan kanker en minder aan harten vaatziekten, het toegenomen draagvlak voor euthanasie binnen de Nederlandse bevolking en de komst van het Expertisecentrum Euthanasie en toegenomen betrokkenheid van huisartsen bij de stervensfase.

\section{Literatuur}

1. Onwuteaka-Philipsen BD, Legemaate J, Van der Heijde A, Van Delden H, Evenblij K, Hammoud I, et al. Derde evaluatie Wet toetsing levensbeëindiging op verzoek en hulp bij zelfdoding. Den Haag: ZonMW, 2017.

2. Heins $M$, Donker G, Versteeg S, Korevaar J. Ontwikkelingen in het aantal euthanasiegevallen en achterliggende factoren. Utrecht: Nivel, 2019.

3. Babitsch B, Gohl D, Von Lengerke T. Re-revisiting Andersen's Behavioral Model of Health Services Use: a systematic review of studies from 1998-2011. Psychosoc Med 2012;9:Doc11.

4. Zimmerman S, Mitchell M, Song Beeber A, Kistler C, Reed D, Chisholm L, et al. Advances in the prevention and control of HAls: Strategies to reduce potentially inappropriate antibiotic prescribing in assisted living and nursing homes. Rockville, MD: Agency for Healthcare Research and Quality, 2014.

5. CBS Statline. Overledenen; geslacht, leeftijd, burgerlijke staat, regio. Den Haag: CBS, 2019. https://opendata.cbs.nl/statline, geraadpleegd december 2019. 
6. Van Delden H, Van der Heide A, Van de Vathorst S, Weyers H, Van Tol DG. Kennis en opvattingen van publiek en professionals over medische besluitvorming en behandeling rond het einde van het leven: Het KOPPEL-onderzoek. Den Haag: ZonMw, 2011.

7. De Hart J, Van Houwelingen P. Christenen in Nederland. Den Haag: SCP, 2018.

8. Buiting HM, Deeg DJ, Knol DL, Ziegelmann JP, Pasman HR, Widdershoven GA, et al. Older peoples' attitudes towards euthanasia and an end-of-life pill in The Netherlands: 2001-2009. J Med Ethics 2012;38:267-73.

9. Koekoek BI. Regie over de plaats van sterven: Een kwantitatieve en kwalitatieve verkenning. Apeldoorn: Universiteit Utrecht, 2014.

10. Middelburg-Hebly M, Galesloot C, van Trigt I, Jansen-Segers M. Palliatieve zorg in beeld. Utrecht: IKNL, 2014.

11. Onwuteaka-Philipsen BD, Rurup ML, Pasman HR, van der Heide A. The last phase of life: who requests and who receives euthanasia or physician-assisted suicide? Med Care 2010;48:596-603.

12. Over de Levenseindekliniek 2018-2019. Den Haag: Expertisecentrum Euthanasie, 2019. http://slk-jaarverslag-beleidsplan. nl/2018-2019, geraadpleegd januari 2020.

13. Visser J. Euthanasie bij toerbeurt. Medisch Contact, 14 maart 2012.

14. CBS Statline. Overledenen; belangrijke doodsoorzaken (korte lijst), leeftijd, geslacht 2019. Den Haag: CBS, 2019. https://opendata.cbs.nl/statline, geraadpleegd december 2019.

15. Evenblij K, Pasman HRW, Van der Heide A, Hoekstra T, Onwuteaka- Philipsen BD. Factors associated with requesting and receiving euthanasia: a nationwide mortality follow-back study with a focus on patients with psychiatric disorders, dementia, or an accumulation of health problems related to old age. BMC Med 2019;17:39.

16. Rurup ML, Muller MT, Onwuteaka-Philipsen BD, Van der Heide A, Van der Wal G, Van der Maas PJ. Requests for euthanasia or physician-assisted suicide from older persons who do not have a severe disease: an interview study. Psychol Med 2005;35:665-71.

17. Brinkman-Stoppelenburg A, Vergouwe $Y$, van der Heide A, Onwuteaka- Philipsen BD. Obligatory consultation of an independent physician on euthanasia requests in the Netherlands: what influences the SCEN physicians judgment of the legal requirements of due care? Health Policy 2014; 115:75-81.

\section{Figuur Aantal mensen bij wie euthanasie is uitgevoerd in Nederland, 2005-2015}

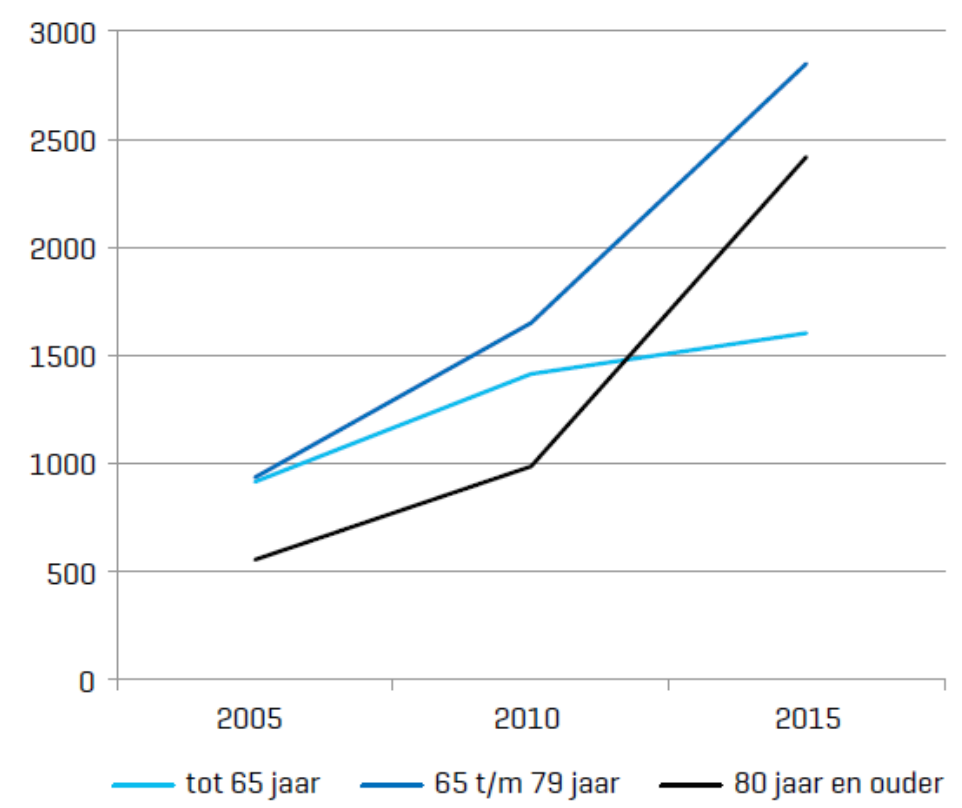

